\title{
Envelhecimento populacional e gastos com saúde: uma análise das transferências intergeracionais e intrageracionais na saúde suplementar brasileira*
}

\author{
Samara Lauar Santos ${ }^{\star *}$ \\ Cássio M. Turra ${ }^{\star \star *}$ \\ Kenya Noronha ${ }^{\star \star \star \star}$
}

\begin{abstract}
O modelo de precificação de planos de saúde no Brasil prevê a imposição de limites de variação das mensalidades por faixa etária, possibilitando a transferência de recursos dos mais jovens, que têm menor risco de utilização, para aqueles em idades mais avançadas. 0 aumento da proporção de idosos nas carteiras dos planos de saúde poderá inviabilizar as transferências intergeracionais e a atual estrutura de precificação. 0 objetivo deste artigo é estimar a magnitude das transferências intergeracionais (entre diferentes grupos de idade) e intrageracionais (em um mesmo grupo de idade) na saúde suplementar brasileira, por meio da análise de dados de uma amostra representativa de operadoras de planos de saúde. Segundo os resultados encontrados, os saldos das transferências intergeracionais foram positivos e ocorrem dos mais jovens para beneficiários de 66 anos ou mais. Os resultados mostram ainda a ocorrência de transferências intrageracionais em duas das faixas etárias definidas pela legislação vigente: 0 a 18 anos e 59 anos ou mais. Finalmente, o exercício de retroprojeção demonstrou que nos últimos 15 anos a sinistralidade nos planos individuais apresentou constante aumento, indicando risco crescente de insuficiência das mensalidades para fins de custeio das despesas no médio prazo, em razão do envelhecimento populacional.
\end{abstract}

Palavras-chave: Envelhecimento populacional. Gastos com saúde. Saúde suplementar brasileira. Transferências intergeracionais. Transferências intrageracionais.

\footnotetext{
* O presente trabalho foi realizado com apoio da Coordenação de Aperfeiçoamento de Pessoal de Nível Superior (Capes), código de financiamento 001. Cassio M. Turra e Kenya Noronha agradecem o apoio recebido do Conselho Nacional de Desenvolvimento Científico e Tecnológico (CNPq). Uma versão anterior desse artigo foi apresentada no encontro da Abep, 2018. Agradecemos às professoras Monica Viegas e Simone Wajnman, além de dois pareceristas anônimos, pelos comentários recebidos em versões anteriores desse trabalho.

${ }^{* *}$ Centro de Desenvolvimento e Planejamento Regional (Cedeplar), Universidade Federal de Minas Gerais (UFMG), Belo Horizonte-MG, Brasil (lauar.samara@gmail.com; https://orcid.org/0000-0003-3764-9500).

*** Faculdade de Ciências Econômicas (Face), Universidade Federal de Minas Gerais (UFMG), Belo Horizonte-MG, Brasil (turra@cedeplar.ufmg.br; https://orcid.org/0000-0003-4051-3567).

**** Faculdade de Ciências Econômicas (Face), Universidade Federal de Minas Gerais (UFMG), Belo Horizonte-MG, Brasil (knoronha@cedeplar.ufmg.br; https://orcid.org/0000-0002-7174-6710).
} 


\section{Introdução}

A estrutura etária de uma população em um determinado período é resultante da dinâmica populacional observada nos anos anteriores. No Brasil, para a média de sua população, o processo de transição demográfica iniciou-se na década de 1930 com o declínio das taxas de mortalidade, especialmente infantil, sendo que até o final dos anos 1960 o nível da fecundidade manteve-se praticamente constante. Como consequência, entre as décadas de 1940 e de 1970, a distribuição etária brasileira praticamente não sofreu mudanças, rejuvenescendo ligeiramente com a queda da mortalidade. A proporção de pessoas com menos de 20 anos correspondeu entre $52 \%$ e $53 \%$ da população total, enquanto o segmento acima de 65 anos permaneceu entre 2,4\% e 3,1\%. A partir de meados dos anos 1960, especialmente com o declínio das taxas de fecundidade, iniciou-se um processo de mudanças profundas na estrutura etária da população brasileira (CARVALHO et al., 1998; CARVALHO; GARCIA, 2003).

Inicialmente, observou-se um aumento mais rápido da população em idade adulta em relação à total. Gradualmente, as maiores taxas de crescimento foram se concentrando em idades mais elevadas, acelerando o processo de envelhecimento populacional. 0 declínio da fecundidade tem sido o principal fator responsável pelas mudanças na estrutura etária da população brasileira, e espera-se que os ganhos de longevidade desempenhem um papel crescente nas próximas décadas (MYRRHA et al., 2012; MYRRHA et al., 2017). Segundo projeções do IBGE, a proporção de pessoas acima de 60 anos aumentará de $11 \%$, em 2010, para 32\%, em 2060, ao passo que a população acima de 80 anos crescerá de $2 \%$ para $8 \%$ nesse mesmo período.

O contexto de envelhecimento populacional afeta diretamente o sistema de saúde, uma vez que os padrões de gastos com saúde têm diferenças significativas em função da idade. As despesas assistenciais apresentam alto custo na infância e significativo aumento com o avançar da idade, principalmente nas últimas décadas de vida (GABRIELE et al., 2005; RICHARDSON; ROBERTSON, 1999). Os maiores gastos entre os idosos refletem o padrão de morbidade deste grupo, com maior prevalência de doenças crônicas degenerativas, o que implica maior consumo de serviços de saúde, maiores taxas de internação hospitalar, bem como maior permanência em internação (CUTLER; MEARA, 1998; KEERAN, 2004; KILSZTAJN et al., 2002; ANDRADE et al., 2010; BERENSTEIN, 2005; REIS et al., 2016).

0 aumento dos gastos com saúde, ocasionado pelo envelhecimento da população, tem impulsionado o debate sobre a sustentabilidade dos serviços de saúde oferecidos tanto pelo Sistema Único de Saúde (SUS) quanto pela saúde suplementar. No caso dessa última, há uma preocupação crescente com o tema por duas razões principais. Em primeiro lugar, pela quantidade de famílias brasileiras que estão cobertas por planos de saúde, apesar da universalidade e gratuidade do SUS. Desde 1998, quando a atividade de planos de saúde foi regulamentada no Brasil, a quantidade de beneficiários vinculados a planos médico-hospitalares (com ou sem odontologia) aumentou aproximadamente $52 \%$, passando de 
30,9 milhões para 47,2 milhões, entre 2000 e 2018, com taxas anuais de crescimento sempre positivas, com exceção do período de 2015 a 2017 (ANS, 2018a). A segunda razão decorre dos valores de mensalidades praticados pelas operadoras de planos de saúde (OPS), que precisam manter relação com o risco coberto para que haja equilíbrio atuarial na operação dos planos. A operação de planos de saúde é viabilizada por uma estrutura de financiamento baseada no mutualismo, em que as mensalidades pagas por todos os beneficiários em um período são destinadas para a cobertura das despesas assistenciais de um determinado grupo. Neste sistema de financiamento, denominado regime de repartição simples (pay-as-you-go), as mensalidades são pagas, independentemente da ocorrência do risco, sem formação de reservas individuais (FIPECAFI, 2009).

Uma vez que os gastos com saúde aumentam significativamente em função da idade, a precificação dos planos de saúde deve seguir o mesmo padrão, de forma a manter relação com o risco coberto para garantia do equilíbrio financeiro e atuarial. Entretanto, a regulamentação brasileira impõe limites às variações dos valores de mensalidades por mudança de faixa etária (FIPECAFI, 2009). Esses limites foram definidos, primeiramente, na Resolução n. 6/98 do Conselho de Saúde Suplementar. Segundo esta regulamentação, as mensalidades deveriam observar, no máximo, sete faixas ( 0 a 17 anos, 18 a 29 anos, 30 a 39 anos, 40 a 49 anos, 50 a 59 anos, 60 a 69 anos e 70 anos ou mais), sendo que a mensalidade da última faixa etária não poderia ser superior a seis vezes o valor da mensalidade da primeira e o beneficiário com mais de 60 anos, que participasse de um plano de saúde há mais de dez anos, não poderia sofrer variação da contraprestação ao mudar de faixa etária.

O Estatuto do Idoso (Lei n. 10.741/. 03), publicado em outubro de 2003, vedou a cobrança de mensalidades diferenciadas para idosos em planos de saúde, sendo classificados como idosos as pessoas com idade igual ou superior a 60 anos. Neste contexto, a ANS publicou a Resolução Normativa n. 63/03, que estabeleceu novas regras e definiu o último reajuste por mudança de faixa aos 59 anos, limitando ainda mais as regras de variação dos preços por grupos de idade. A RN n. 63/03 definiu dez faixas-etárias ( 0 a 18 anos, 19 a 23 anos, 24 a 28 anos, 29 a 33 anos, 34 a 38 anos, 39 a 43 anos, 44 a 48 anos, 49 a 53 anos, 54 a 58 anos e 59 anos ou mais), manteve a regra de que a mensalidade da última faixa não poderia ser superior a seis vezes o valor da mensalidade da primeira e incluiu a regra de que a variação acumulada entre a sétima e a décima faixas não poderia ser superior à variação acumulada entre a primeira e a sétima. Considerando a limitação prevista pelo Estatuto do Idoso, todos os beneficiários com 59 anos ou mais devem pagar mensalidades uniformes, embora dentro dessa faixa as despesas assistenciais sejam significativamente maiores para os mais idosos. Ademais, o limite de variação entre a última e a sétima faixa tem como objetivo reduzir os percentuais nos últimos grupos de idade, acima de 49 anos, de tal forma que parte da variação seja diluída nas primeiras faixas.

A transferência líquida de recursos dos indivíduos mais jovens para os idosos (pacto intergeracional) poderá ocorrer à medida que essas restrições impliquem preços 
subsidiados para os grupos de idade mais velhos, isto é, em preços que são inferiores aos custos efetivos gerados por este subgrupo para os planos. A regulamentação pode fazer com que os beneficiários com menor risco (mais jovens) arquem com as despesas excedentes das pessoas em idades mais avançadas, pagando valores superiores à sua utilização esperada. Esse tipo de arranjo pode tornar o plano de saúde uma opção desinteressante financeiramente caso reduza o incentivo à entrada de pessoas jovens aos planos, ocasionando seleção adversa. Ou seja, ao cobrarem o prêmio baseado no risco médio da população a ser segurada (community rating), as OPS geram incentivos para que indivíduos com maior risco de utilizar serviços de saúde tenham maior probabilidade de aderir aos planos relativamente aos de menor risco (MAIA, 2004). Para o Brasil, contudo, as evidências empíricas acerca da seleção adversa não são conclusivas (MAIA, 2012; ALVES, 2004; RESENDE; ZEIDAN, 2010; NUNES et al., 2014). A transferência de recursos entre as gerações nos planos de saúde é viável apenas se os beneficiários mais jovens continuarem a aderir aos planos, mesmo não havendo vantagem financeira, inicialmente, para eles. Com a participação mais alta de jovens, as transferências de recursos para os beneficiários mais velhos podem ser diluídas, resultando em uma transferência per capita mais baixa. À medida que a população envelhece há um aumento da necessidade de transferência para cada indivíduo, uma vez que existe um menor número de pessoas jovens para subsidiar a conta de um número crescente de idosos, o que faz com que aumente a chance de seleção adversa. Portanto, não é certo que as regras vigentes do pacto intergeracional possam ser mantidas no contexto demográfico atual e futuro do país.

Em estudo recente, Turra, Noronha e Andrade (2015) avaliaram a existência e a magnitude do pacto intergeracional no setor de saúde suplementar, bem como sua capacidade de financiamento das OPS. Os resultados encontrados demonstraram que as despesas assistenciais excedem as receitas apenas entre os indivíduos de idade avançada (80 anos e mais), que se beneficiam de transferências de grupos de idade mais jovens. Além disso, as despesas com internações são as grandes responsáveis pelas transferências entre os grupos de idade, dado que o custo médio e a taxa de utilização são maiores nas idades mais elevadas. 0 trabalho dos autores, no entanto, considerou apenas as despesas assistenciais, o que provavelmente minimiza a necessidade de transferências entre gerações.

Além das transferências intergeracionais, pode haver também transferências intrageracionais, que ocorrem dentro das faixas etárias definidas pelas resoluções vigentes, sobretudo nas de maior amplitude, como as de 0 a 18 anos e 59 anos ou mais, uma vez que agrupam indivíduos de diferentes níveis de risco. Resultados de um estudo brasileiro (RIBEIRO, 2005) demonstraram que a taxa de utilização de consultas, que corresponde à relação entre o número de pessoas com pelo menos uma consulta no ano e o número de pessoas expostas ao risco neste mesmo ano, foi de 82,4 entre os recém-nascidos e cerca da metade, 46, para os indivíduos de 18 anos. Além disso, a taxa de internações para os recém-nascidos $(11,5)$ é aproximadamente $85 \%$ superior àquela calculada para os indivíduos de 18 anos $(6,2)$. Em relação à última faixa etária definida pela ANS (59 anos ou mais), 
a taxa de utilização de consultas foi de 71,5 para beneficiários de 59 anos e 75,1 para os de 69 anos. As diferenças são ainda maiores para a taxa de internação, cerca de $44 \%$ superior para beneficiários de 69 anos em relação aos de 59 anos. Estes resultados confirmam que, dentro de um mesmo grupo etário definido pela ANS, há variações significativas no risco de utilização dos serviços de saúde, o que pode gerar um volume considerável de transferências de recursos líquidos entre indivíduos de uma mesma faixa etária.

Diante do exposto, busca-se, neste trabalho, analisar o atual padrão e o volume de transferências inter e intrageracionais na saúde suplementar brasileira. A análise inclui as várias receitas e despesas envolvidas na operação de planos de saúde, além das assistenciais que são mais frequentemente consideradas em estudos dessa natureza. Também pretende-se avaliar o efeito puro (exclusivo) das mudanças na distribuição etária sobre o pacto intergeracional ao longo de um período de 15 anos, a partir da retroprojeção da relação entre despesas assistenciais e mensalidades. Espera-se, com os resultados desse trabalho, ampliar a discussão sobre a sustentabilidade da atual estrutura de precificação dos planos de seguro de saúde no Brasil, em um contexto de rápido envelhecimento populacional.

\section{Metodologia}

Base de dados

A base de dados contempla o histórico de beneficiários no período de 2000 a 2015 , além das mensalidades e despesas assistenciais (ambulatoriais e hospitalares) referentes a 2015. 0 nível de detalhamento das informações é superior ao observado nas bases públicas disponibilizadas pela ANS. Os dados foram fornecidos por 11 operadoras de planos de saúde, nas modalidades cooperativas médicas e medicinas de grupo, que representam aproximadamente 780 mil beneficiários em 2015, correspondendo a 1,6\% do total de beneficiários vinculados a planos médico-hospitalares no Brasil nesse ano. Os dados não são identificados por usuários e operadoras e foram disponibilizados por uma empresa de consultoria atuarial e regulatória especializada no setor. Sua utilização foi autorizada por cada uma das operadoras contribuintes. Visando testar a validade externa da amostra, comparou-se a distribuição etária observada na população em estudo com o padrão geral registrado no setor pela ANS em 2015. Não foram identificadas diferenças importantes, apenas uma distribuição por idade ligeiramente mais envelhecida na amostra relativamente ao universo da ANS. A diferença nas idades médias foi de apenas 0,9 ano, resultado que minimiza a possibilidade de viés de seleção por idade na amostra.

Para estimar as transferências líquidas de forma mais abrangente, foram obtidas as demonstrações contábeis das operadoras, que são publicadas pela ANS. A partir das demonstrações contábeis é possível obter informações sobre outras despesas e receitas, tais como despesas administrativas, comerciais e resultado financeiro, além das assistenciais que já estavam presentes originalmente na base de dados. Os documentos contábeis 
correspondem à fonte de informação oficial perante à ANS, sendo que trimestralmente as operadoras devem encaminhar os balancetes por meio de um relatório denominado Documento de Informações Periódicas das Operadoras de Planos de Assistência à Saúde (Diops). Há muita consistência entre os valores de mensalidades e despesas assistenciais informados originalmente na base de dados da amostra e os valores reportados pelas mesmas operadoras no Diops-ANS (diferenças inferiores a $2 \%$ ), o que aumenta a segurança para acrescentar neste estudo as demais informações contábeis presentes apenas no Diops-ANS.

\section{Métodos}

Para a estimativa das transferências inter e intrageracionais na saúde suplementar, a análise está dividida em quatro partes. Em primeiro lugar, descreve-se a população em estudo, por meio da análise da evolução da carteira de beneficiários vinculados às operadoras consideradas no período de 2000 a 2015, além dos padrões de receitas, despesas e frequências de utilização, observados em 2015. Para isso, foram utilizadas medidas relativamente simples, como a distribuição por idade das despesas e receitas. Em seguida, foram mensuradas as transferências intergeracionais propriamente ditas a partir das distribuições das receitas e despesas por idade simples, ou seja, utilizando uma categorização etária menos restritiva do que a determinada pelas regras de precificação da ANS. Essa etapa é importante porque permite mensurar as transferências entre idades empregando o máximo de informações disponíveis na base de dados.

Para o cálculo das transferências intergeracionais, utilizaram-se diferentes medidas. Inicialmente, foram calculados dois indicadores: a sinistralidade média e por idade, que corresponde à razão entre as despesas assistenciais e mensalidades; e a sinistralidade combinada ampliada média e por idade, que se refere à razão entre a soma de todas as despesas (administrativas, comerciais e assistenciais) e a soma de todas as receitas (mensalidades e resultado financeiro) (ANS, 2015). Além disso, os resultados das OPS foram desagregados por idade. Como no caso da sinistralidade, utilizaram-se duas medidas: 0 resultado operacional (RO), limitado às despesas assistenciais e receitas de mensalidades; e o resultado líquido ( $R L)$, que considera todas as receitas e despesas. A comparação de medidas com diferentes níveis de abrangência em relação às receitas e despesas é uma importante contribuição desse trabalho, uma vez que permite mensurar melhor a realidade financeira das OPS, evitando que possíveis efeitos do envelhecimento sejam minimizados. Portanto, seguindo as formulações de Turra et al. (2015), o resultado operacional (RO) foi decomposto da seguinte forma:

$$
\begin{aligned}
& \mathrm{RO}^{\mathrm{t}}=\sum_{\mathrm{i}=1}^{\mathrm{n}}\left(\mathrm{RM}_{\mathrm{i}}-\mathrm{DM}_{\mathrm{i}}\right) \times\left(\mathrm{B}_{\mathrm{i}}\right) \\
& \therefore \mathrm{RO}^{\mathrm{t}}=\sum_{\mathrm{i}=1}^{\mathrm{n}}\left(\mathrm{TM}_{\mathrm{i}}\right) \times\left(\mathrm{B}_{\mathrm{i}}\right)
\end{aligned}
$$

Em que:

$R O^{t}$ : resultado operacional (saldo das transferências) em 2015;

$R M_{i}^{t}$ : receita média de mensalidades em 2015 na idade $i$; 
$D M_{i}^{t}$ : despesa assistencial média em 2015 na idade $i$;

$B_{i}{ }^{t}$ : beneficiários expostos em 2015 na idade $i$;

$T M_{i}{ }^{t}$ : transferência média por beneficiário exposto em 2015 na idade $i$.

Os beneficiários expostos correspondem à quantidade de beneficiários ativos em 2015, ponderada pelo tempo de exposição de cada indivíduo no ano.

Por sua vez, na versão estendida da medida anterior, o resultado líquido (que inclui todas as receitas e despesas) foi decomposto conforme mostrado a seguir:

$$
\begin{aligned}
& \mathrm{RL}^{\mathrm{t}}=\sum_{\mathrm{i}=1}^{\mathrm{n}}\left(\mathrm{RM}_{\mathrm{i}}-\mathrm{DM}_{\mathrm{i}}-\mathrm{DA}_{\mathrm{i}}-\mathrm{DC}_{\mathrm{i}}+R F_{\mathrm{i}}\right) \times\left(\mathrm{B}_{\mathrm{i}}\right) \\
& \therefore \mathrm{RL}^{\mathrm{t}}=\sum_{\mathrm{i}=1}^{\mathrm{n}}\left(\mathrm{TM}_{\mathrm{i}}\right) \times\left(\mathrm{B}_{\mathrm{i}}\right)
\end{aligned}
$$

Em que:

$R L^{t}$ : resultado líquido (saldo líquido das transferências) em 2015;

$R M_{i}^{t}$ : receita média de mensalidades em 2015 na idade $i$;

$D M_{i}^{t}$ : despesa assistencial média em 2015 na idade $i$;

$\mathrm{DA}_{\mathrm{i}}^{\mathrm{t}}$ : despesa administrativa média em 2015 na idade $i$;

$D C_{i}^{t}$ : despesa comercial média em 2015 na idade $i$;

$R F_{i}{ }_{i}$ : resultado financeiro médio em 2015 na idade $i$;

$B_{i}{ }^{t}$ : beneficiários expostos em 2015 na idade $i$;

$T M_{i}^{t}$ : transferência líquida média por beneficiário em 2015 na idade $i$.

A distribuição por idade das despesas administrativas e comerciais e dos resultados financeiros foi realizada proporcionalmente à quantidade de beneficiários expostos. Como já ressaltado, a decomposição das transferências no âmbito do resultado líquido tem como objetivo apresentar uma estimativa mais fidedigna com a realidade das operadoras, uma vez que as mensalidades são destinadas também para o custeio de outras despesas, além das assistenciais, tais como as despesas administrativas e comerciais. Além disso, as operadoras possuem recursos provenientes de outras fontes, tais como as receitas financeiras.

Na terceira etapa dos resultados, as transferências intergeracionais foram novamente estimadas, utilizando as dez faixas etárias determinadas pela ANS. Como o padrão etário de precificação vigente é muito restritivo, impondo grupos de idades amplos, passam a existir, simultaneamente, transferências inter e intrageracionais. No caso dessas últimas, focamos especialmente nos grupos de 0-18 e 59 anos ou mais pela heterogeneidade de riscos presentes nesses grupos e sua importância do ponto de vista dos padrões de morbidade e mortalidade. Para tanto, estimaram-se as mesmas medidas de sinistralidade, além do valor médio dos resultados operacional e líquido por faixa etária.

$\mathrm{Na}$ última etapa do trabalho, apresenta-se uma retroprojeção das transferências intergeracionais, cujo objetivo é estimar o efeito exclusivo das transformações etárias no pacto intergeracional ao longo do tempo. Para isso foram consideradas a distribuição etária observada nas OPS por idade simples, no período de 2000 a 2015 , e as despesas assistenciais e mensalidades médias observadas em 2015, sem realizar quaisquer ajustes 
financeiros e nem controlar pela influência de qualquer outra variável. Ou seja, trata-se de uma análise meramente contrafactual que pretende responder qual teria sido o volume e padrão de transferências em 2015 caso o contexto demográfico vigente fosse o equivalente ao de anos anteriores. Como a retroprojeção contempla apenas as transferências no âmbito do resultado operacional, não foram consideradas, nesse caso, as despesas administrativas, comerciais e receitas provenientes de resultado financeiro. As medidas incluídas na análise contrafactual são definidas pelas equações (3) e (4):

$\operatorname{Dr}_{\mathrm{i}}^{\mathrm{t}}=\mathrm{B}_{\mathrm{i}}^{\mathrm{t}} \times \mathrm{DM}_{\mathrm{i}}^{2015}$

Em que:

$\operatorname{Dr}_{\mathrm{i}}^{\mathrm{t}}$ : despesas assistenciais retroprojetadas na idade $i$ no ano $t$;

$\mathrm{B}_{\mathrm{i}}^{\mathrm{t}}$ : distribuição etária percentual na idade $i$ no ano $t$;

$\mathrm{DM}_{\mathrm{i}}^{2015}$ : despesa assistencial média observada na idade $i$ em 2015.

$\operatorname{Rr}_{\mathrm{i}}^{\mathrm{t}}=\mathrm{B}_{\mathrm{i}}^{\mathrm{t}} \times \mathrm{RM}_{\mathrm{i}}^{2015}$

Em que:

$\mathrm{Rr}_{\mathrm{i}}^{\mathrm{t}}$ : mensalidades retroprojetadas na idade $i$ no ano $t$;

$\mathrm{B}_{\mathrm{i}}^{\mathrm{t}}$ : distribuição etária percentual na idade $i$ no ano $t$;

$\mathrm{RM}_{\mathrm{i}}^{2015}$ : mensalidade média observada na idade $i$ no ano de 2015.

A partir desses dois indicadores, estimou-se a sinistralidade retroprojetada conforme definido pela equação (5):

$\mathrm{Sr}^{\mathrm{t}}=\frac{\sum_{i=0}^{\omega} \mathrm{Dr}_{\mathrm{i}}^{\mathrm{t}}}{\sum_{i=0}^{\omega} \operatorname{Rr}_{\mathrm{i}}^{\mathrm{t}}}$

Em que:

$\mathrm{Sr}^{\mathrm{t}}$ : sinistralidade retroprojetada no ano $t$;

$\mathrm{Rr}_{\mathrm{i}}^{\mathrm{t}}$ : mensalidades retroprojetadas na idade $i$ no ano $t$;

$\operatorname{Dr}_{\mathrm{i}}^{\mathrm{t}}$ : despesas assistenciais retroprojetadas na idade $i$ no ano $t$.

Ressalta-se que, em todas as etapas do trabalho, as análises foram realizadas segundo três tipos de contratação: planos individuais ou familiares; coletivos empresariais; e coletivos por adesão. Os contratos individuais ou familiares ocorrem por meio de pessoa física, enquanto os coletivos são realizados por pessoa jurídica. Neste último caso, a cobertura assistencial é oferecida à população delimitada vinculada à pessoa jurídica por relação empregatícia ou estatutária (coletivo empresarial) ou por caráter profissional, classista ou setorial (coletivo por adesão). Optou-se por realizar esta segregação porque o padrão da composição etária, bem como das receitas e despesas, diferencia-se muito entre os tipos de contratação. Os planos individuais, por exemplo, possuem regulamentações mais restritivas no que tange às políticas de cancelamento e reajuste, o que permite menos ação por parte das operadoras. Dessa forma, mesmo se o contrato for deficitário, a operadora não pode cancelá-lo por decisão unilateral, o que pode resultar em incentivo para a permanência dos beneficiários de maior risco, tornando a massa de planos individuais mais envelhecida do que as demais contratações. Já os planos 
coletivos empresariais tendem a apresentar população mais rejuvenescida em função do padrão etário do mercado de trabalho.

Ademais, há diferenças nas frequências de utilização segundo o tipo de contratação, de forma que os planos coletivos empresariais, em geral, apresentam menor nível de utilização quando comparados aos individuais, não apenas em função da composição etária da massa. Neste contexto, as análises segregadas por tipo de contratação têm como objetivo adequar os resultados encontrados ao padrão de cada modelo contratual, considerando as particularidades regulatórias e assistenciais das massas em questão.

\section{Resultados}

\section{Análise descritiva}

As transferências inter e intrageracionais na saúde suplementar estão diretamente relacionadas às características da população, principalmente idade. Dessa forma, a fim de descrever a população em estudo, nesta seção inicial será realizada uma breve análise da evolução da carteira de beneficiários vinculados às operadoras consideradas na amostra no período de 2000 a 2015 . Além disso, serão analisados os padrões de receitas, despesas e frequências de utilizações, observados em 2015. Nessa etapa, não nos restringiremos às faixas etárias impostas pela ANS e procuraremos examinar as variáveis de interesse segundo todo o espectro possível de idades.

A carteira de beneficiários das operadoras selecionadas contempla, aproximadamente, 780 mil expostos em 2015, sendo que, nos últimos 15 anos (2000-2015), a taxa de crescimento média anual foi de $8,6 \%$. Ressalta-se que essa taxa foi negativa em 2009 e significativamente baixa em 2015. A redução das inclusões e o aumento das exclusões nestes anos foram impulsionados por crises econômico-financeiras, que afetaram a renda dos usuários. Quanto à evolução da distribuição etária dos beneficiários expostos, verificou-se que no período analisado houve mudanças significativas no padrão. Em 2015 foi observada uma população mais envelhecida, com maior proporção de pessoas acima de 25 anos em relação a 2000 (Gráfico 1).

A distribuição etária dos beneficiários nos planos de saúde depende de vários fatores, além dos observados na população como um todo. Na população total a quantidade de pessoas em cada idade é resultado apenas do histórico das taxas de fecundidade, mortalidade e migração. Nos planos de saúde há ainda outros fatores específicos, tais como os diferenciais de mortalidade dos beneficiários em relação à população total e as taxas de adesão e cancelamento dos planos impactadas pelo mercado de trabalho, níveis de renda, oferta regional de planos, dentre outros fatores (TURRA et al., 2015).

A composição etária varia significativamente segundo o tipo de contratação dos planos (Gráfico 1). Os planos individuais ou familiares apresentam distribuição etária mais envelhecida, uma vez que a adesão é livre, ao passo que os planos coletivos empresariais 
possuem maior proporção de pessoas em idade ativa, cuja adesão ocorre principalmente por meio do empregador. Ademais, os planos individuais são mais “engessados”, uma vez que permitem menos ação por parte das operadoras, como por exemplo rescisão apenas em caso de fraude e/ou falta de pagamento e reajuste limitado a índice divulgado pela ANS. Dessa forma, caso haja contratos individuais deficitários, as operadoras não podem optar por cancelá-los por decisão unilateral, nem definir um reajuste superior ao que é fixado pela ANS. Considerando o padrão de crescimento dos gastos com saúde em função da idade, há incentivo financeiro para permanência de beneficiários com idades mais avançadas, uma vez que o limite de reajuste a ser aplicado pode não ser suficiente para equilibrar o contrato, de forma a manter o nível dos gastos superior às mensalidades pagas, além da impossibilidade de cancelamento por parte da operadora.

GRÁFICO 1

Pirâmide etária dos beneficiários, por sexo, segundo tipo de contratação - 2000-2015
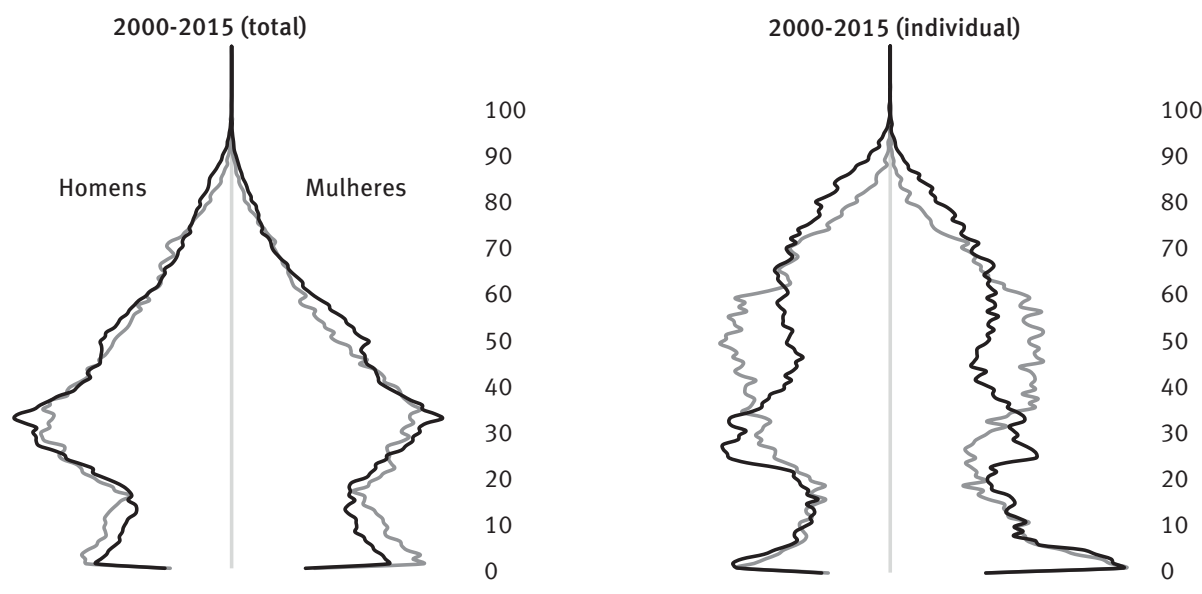

2000-2015 (coletivo empresarial)
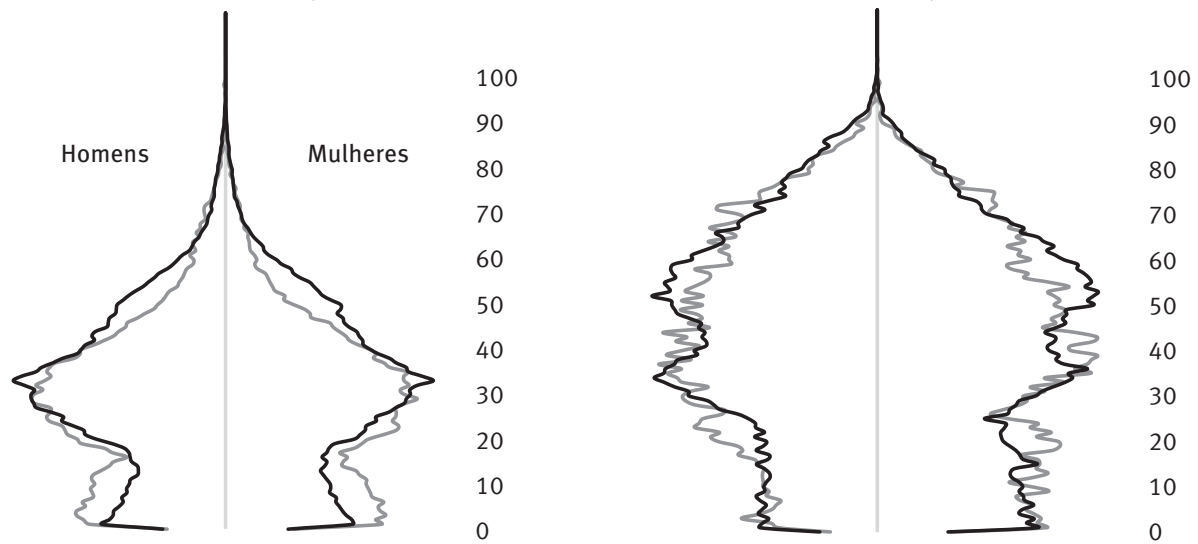

$-2000-2015$

Fonte: Amostra de operadoras de planos de saúde. Elaboração dos autores. 
Observou-se ainda que, de forma geral, a razão de dependência de idosos das operadoras consideradas na amostra, independentemente do tipo de contratação, é maior do que a verificada para a população brasileira em todos os anos analisados. Em relação aos tipos de planos, a razão de dependência de idosos encontrada nos planos individuais e coletivos por adesão foi superior à constatada para o total do Brasil, ao passo que para os planos coletivos empresariais observou-se o contrário. No período analisado, houve um aumento da razão de dependência dos idosos no grupo de beneficiários com planos individuais, enquanto nos planos coletivos empresariais essa se manteve praticamente constante. Nos planos coletivos por adesão houve uma redução da razão nos primeiros anos e um posterior aumento a partir de 2008. Em relação à composição da carteira segundo o sexo dos beneficiários, verificou-se que não houve alteração significativa nos 15 anos analisados. Em 2000, aproximadamente 54\% dos beneficiários expostos eram mulheres, enquanto em 2015 este percentual correspondia a aproximadamente $53 \%$. Tal composição é semelhante à observada no setor de saúde suplementar como um todo, uma vez que, segundo dados gerais publicados pela ANS, 53\% dos beneficiários vinculados aos planos de saúde em 2015 eram mulheres.

Ao todo, as 11 operadoras consideradas na análise arrecadaram cerca de $R \$ 1,6$ bilhão referentes a mensalidades em 2015, o que representa cerca de $1 \%$ do faturamento total do setor nesse período. Do ponto de vista agregado, a maior parte dessa receita foi realizada por beneficiários entre 18 e 65 anos (aproximadamente 68\%), sendo que a idade média de pagamento corresponde a 45 anos. A distribuição das mensalidades totais é influenciada pelo padrão etário da carteira de beneficiários, o que justifica a concentração nas idades ativas. Se estimarmos as mensalidades médias por idade, que são ponderadas pela quantidade de beneficiários expostos em cada idade, observam-se valores mais altos entre os beneficiários idosos, de forma que a mensalidade média correspondente à última faixa etária (59 anos ou mais, segundo distribuição definida pela ANS) é cerca de quatro vezes maior do que aquela referente à primeira faixa (0 a 18 anos, segundo distribuição definida pela ANS), o que é esperado em função do padrão de risco por idade e da própria regulamentação de preços da ANS (Gráfico 2). A mensalidade média em 2015 foi de R\$170, sendo que os valores médios pagos nas idades acima de 45 anos são superiores a esta referência. Além disso, há diferenças significativas entre as mensalidades médias apuradas segundo dependência, tipo de contratação e forma de participação. Os valores pagos pelos beneficiários titulares são mais altos do que os realizados pelos dependentes e agregados, bem como são cobradas maiores mensalidades para os planos individuais e não coparticipativos (planos em que não há previsão de cobrança de coparticipação no momento da utilização dos serviços). Essas diferenças de preços refletem os padrões de risco destes grupos e suas composições etárias, bem como o pacote de benefícios do plano de saúde contratado (com ou sem coparticipação). 
GRÁFICO 2

Mensalidades e despesas assistenciais médias por idade - 2015
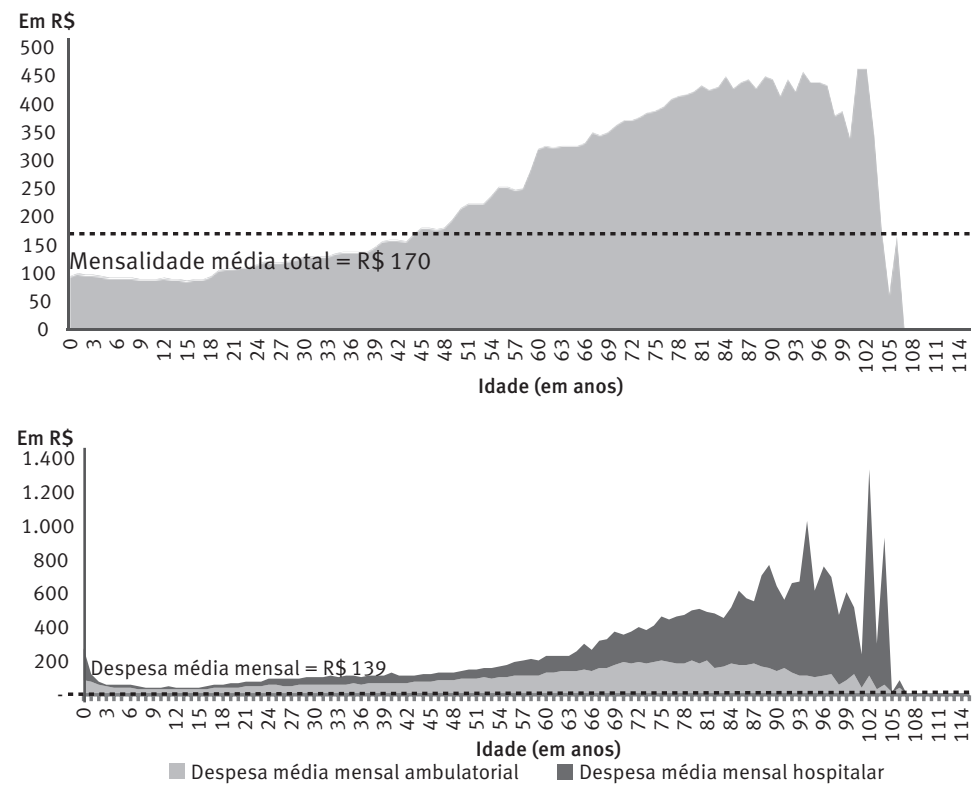

Fonte: Amostra de operadoras de planos de saúde. Elaboração dos autores.

As operadoras analisadas registraram cerca de $\mathrm{R} \$ 1,3$ bilhão em despesas assistenciais em 2015, sendo aproximadamente R\$ 580 milhões (45\%) referentes a despesas hospitalares e R $\$ 720$ milhões (55\%) em despesas ambulatoriais. Em torno de $63 \%$ das despesas totais foram realizadas por beneficiários entre 18 e 65 anos, de forma que a idade média de utilização corresponde a 48 anos. Nas idades de 1 a 64 anos, a maior parte das despesas assistenciais refere-se a procedimentos ambulatoriais, enquanto entre os menores de um ano e idades acima de 65 anos há mais despesas realizadas com internações. A fim de refletir o padrão das despesas assistenciais sem o efeito da composição etária, foram estimadas as despesas médias mensais por idade. Nesta análise, verificou-se que os gastos crescem significativamente em função da idade, corroborando os resultados encontrados na literatura (GABRIELE et al., 2005; RICHARDSON; ROBERTSON, 1999; CUTLER; MEARA, 1998; KEERAN, 2004; KILSZTAJN et al., 2002; ANDRADE et al., 2010). A despesa média mensal observada em 2015 foi de R\$139, sendo que nas idades de 0 ano e acima de 49 anos os gastos registrados são superiores à média apurada (Gráfico 2). Do ponto de vista das definições utilizadas pela ANS, a despesa média da última faixa etária (59 anos ou mais) é aproximadamente 5,5 vezes maior do que a observada na primeira faixa (0 a 18 anos).

Ao se analisar a despesa média por idade e tipo de procedimento (resultados disponíveis mediante solicitação), verificaram-se, em todos os grupos de procedimentos analisados, maiores despesas nas idades mais avançadas. Uma razão para esse padrão é o crescimento das taxas de utilização com a idade. Considerando a classificação de idade 
da ANS, enquanto na faixa etária de 0 a 18 anos a quantidade média anual de consultas corresponde a quatro, na última faixa (59 anos ou mais) é de aproximadamente sete. Há uma variação ainda mais expressiva quando se trata de exames e terapias, em que a primeira faixa ( 0 a 18 anos) apresenta uma frequência média de sete utilizações por ano, contra 29 no grupo de beneficiários com 59 anos ou mais.

O mesmo padrão de utilização é observado nas internações (resultados disponíveis mediante solicitação). 0 percentual de beneficiários internados aumenta significativamente em função da idade. Em relação à despesa por beneficiário internado, o valor médio em 2015 foi de R $\$ 9.096$. Os beneficiários em idades mais avançadas possuem maiores gastos porque demandam serviços mais caros, além de permanecerem mais tempo no hospital. 0 número médio de diárias observado em 2015 para a amostra de operadoras analisadas foi 4,8 , sendo que nas idades de 0 a 4 anos e acima de 64 anos a permanência média observada foi superior, chegando a 12 dias entre indivíduos acima de 80 anos de idade. Em relação às faixas etárias da ANS, a despesa média por internado dos beneficiários de 0 a 18 anos foi de aproximadamente 6 mil reais, enquanto para aqueles acima de 59 anos esse valor foi de 14 mil reais, cerca de 2,35 vezes superior. Finalmente, as despesas variam significativamente segund o o tipo de contratação, forma de participação, sexo e dependência, sendo mais elevadas entre os beneficiários titulares, do sexo feminino, vinculados a planos individuais e não coparticipativos, conforme detalhado na Tabela 1.

TABELA 1

Despesas assistenciais médias mensais por beneficiário, segundo tipo de contratação, forma de participação, sexo e dependência - 2015

Em reais

\begin{tabular}{|c|c|c|c|}
\hline \multirow[b]{2}{*}{ Variáveis } & \multicolumn{3}{|c|}{ Despesas assistenciais médias mensais } \\
\hline & Ambulatorial & Hospitalar & $\begin{array}{l}\text { Ambulatorial } \\
\text { +hospitalar }\end{array}$ \\
\hline \multicolumn{4}{|l|}{ Tipo de contratação } \\
\hline Individual & 116,87 & 100,42 & 217,29 \\
\hline Coletivo empresarial & 66,41 & 46,88 & 113,28 \\
\hline Coletivo adesão & 82,93 & 80,80 & 163,73 \\
\hline \multicolumn{4}{|l|}{ Forma de participação } \\
\hline Coparticipativo & 73,50 & 63,88 & 137,39 \\
\hline Não coparticipativo & 94,88 & 58,99 & 153,88 \\
\hline \multicolumn{4}{|l|}{ Sexo } \\
\hline Homens & 63,52 & 57,82 & 121,34 \\
\hline Mulheres & 89,51 & 65,86 & 155,37 \\
\hline \multicolumn{4}{|l|}{ Dependência } \\
\hline Titular & 88,78 & 71,73 & 160,51 \\
\hline Dependente & 67,90 & 51,38 & 119,28 \\
\hline Agregado & 42,20 & 88,25 & 130,45 \\
\hline
\end{tabular}

Fonte: Amostra de operadoras de planos de saúde. Elaboração dos autores. 


\section{Transferências intergeracionais por idade simples}

Os padrões de despesas e receitas, bem como a crescente proporção de beneficiários idosos, combinados com o aparato regulatório de precificação de planos de saúde, têm gerado dúvidas sobre a sustentabilidade do pacto intergeracional neste mercado. Em tal contexto, a fim de compreender a magnitude das transferências intergeracionais, serão identificadas as idades que, em média, os recursos líquidos são transferidos ou recebidos e os saldos das transferências em 2015, segundo o tipo de contratação dos planos. Da mesma forma que na descrição da população em estudo, nessa etapa não restringiremos a análise às faixas etárias impostas pela ANS, que serão tratadas na próxima seção.

Inicialmente, é importante descrever a relação entre despesas e receitas, por meio dos índices de sinistralidade. Conforme demonstrado no Gráfico 3, o índice de sinistralidade (razão entre despesas assistenciais e mensalidades apenas) médio observado em 2015 na carteira analisada foi de $82 \%$, sendo que nos grupos de idade de 0 a 4 anos e acima de 70 anos os valores de despesas excederam as mensalidades, sugerindo a existência de transferências intergeracionais, na média, dos mais jovens para as idades mais avançadas.

\section{GRÁFICO 3}

Sinistralidade e sinistralidade combinada ampliada, por faixa etária - 2015

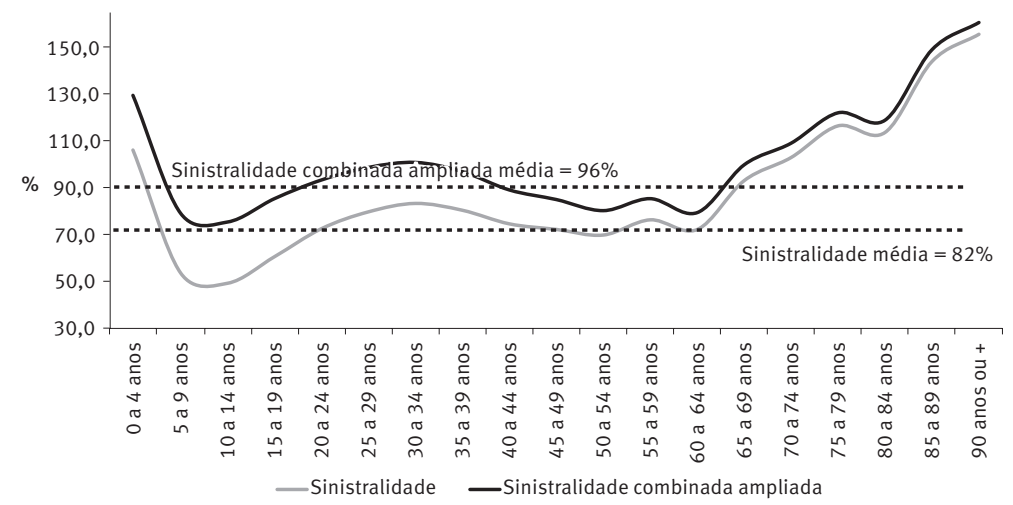

Fonte: Amostra de operadoras de planos de saúde. Elaboração dos autores.

O cálculo da sinistralidade no âmbito do resultado operacional considera apenas as mensalidades e despesas assistenciais. No entanto, as mensalidades também são destinadas para o pagamento de outras despesas, tais como administrativas (14,8\% do total) e comerciais ( $0,4 \%$ do total). Por outro lado, em relação às receitas, aproximadamente $98,8 \%$ referem-se às mensalidades, mas há outros $1,2 \%$ provenientes de resultado financeiro. Com os dados contábeis completos, foi apurado o índice de sinistralidade combinado ampliado, que corresponde à razão entre o total de despesas e o total de receitas. A sinistralidade combinada ampliada média em 2015 foi de $96 \%$, superior, portanto, aos $82 \%$ estimados anteriormente quando utilizaram-se apenas as despesas operacionais e mensalidades. Ou seja, em média, resta um ganho financeiro para as operadoras de apenas $4 \%$ das receitas. Novamente, nas 
faixas de 0 a 4 anos e acima de 65 anos, os valores de despesas excedem as receitas. Além disso, a sinistralidade também é ligeiramente superior a 100\% no grupo etário 30 a 34 anos, refletindo as maiores despesas com a maternidade e causas externas (Gráfico 3).

A Tabela 2 apresenta a síntese dos resultados encontrados levando em conta toda a contabilidade das OPS. As transferências ocorrem de forma distinta segundo o tipo de contratação. 0 índice é igual a 95\% nos planos individuais, $99 \%$ nos coletivos empresariais e $91 \%$ nos coletivos por adesão.

TABELA 2

Transferências intergeracionais por idade simples - resultado líquido 2015

\begin{tabular}{|c|c|c|c|c|}
\hline Variáveis & $\begin{array}{l}\text { Contratação } \\
\text { individual }\end{array}$ & $\begin{array}{l}\text { Contratação } \\
\text { empresarial }\end{array}$ & $\begin{array}{l}\text { Contratação } \\
\text { coletiva por } \\
\text { adesão }\end{array}$ & Total \\
\hline \multicolumn{5}{|l|}{ Doadores líquidos } \\
\hline Idade (em anos) & 0 a 65 & 0 a 65 & 0 a 65 & 0 a 65 \\
\hline Idade média (em anos) & 31,0 & 30,3 & 35,8 & 31,4 \\
\hline Expostos & $105.039,67$ & $473.233,32$ & $134.772,57$ & $713.045,42$ \\
\hline $\begin{array}{l}\text { Receita total (mensalidades + RF) } \\
\text { (em R\$) }\end{array}$ & $269.686 .801,37$ & $750.337 .411,21$ & $271.082 .333,36$ & 1.291.106.545,94 \\
\hline Receita média (em R\$) & $2.567,48$ & $1.585,55$ & $2.011,41$ & $1.810,69$ \\
\hline $\begin{array}{l}\text { Despesa total (despesas assist. + DA } \\
\text { + DC) (em } R \$)\end{array}$ & $217.583 .757,05$ & $726.378 .982,27$ & $225.634 .565,10$ & $1.169 .597 .304,43$ \\
\hline Despesa média (em R\$) & $2.071,44$ & $1.534,93$ & $1.674,19$ & $1.640,28$ \\
\hline Transferência média (em R\$̦) & 496,03 & 50,63 & 337,22 & 170,41 \\
\hline \multicolumn{5}{|l|}{ Receptores líquidos } \\
\hline Idade (em anos) & $66 \mathrm{ou}+$ & 66 ou + & 66 ou + & 66 ou + \\
\hline Idade média (em anos) & 76,0 & 73,7 & 75,2 & 75,2 \\
\hline Expostos & $24.698,33$ & $14.707,68$ & $26.319,43$ & $65.725,58$ \\
\hline $\begin{array}{l}\text { Receita total (mensalidades + RF) } \\
\text { (em R\$) }\end{array}$ & $123.687 .231,55$ & $62.995 .404,27$ & $126.112 .050,28$ & $312.794 .686,10$ \\
\hline Receita média (em R\$) & $5.007,92$ & $4.283,16$ & $4.791,60$ & $4.759,10$ \\
\hline $\begin{array}{l}\text { Despesa total (despesas assist. + DA } \\
+\mathrm{DC})(\text { em R\$) }\end{array}$ & $155.645 .302,72$ & $75.751 .912,34$ & $135.513 .806,04$ & 366.911.021,09 \\
\hline Despesa média (em R\$) & $6.301,85$ & $5.150,50$ & $5.148,81$ & $5.582,47$ \\
\hline Transferência média (em R\$) & $-1.293,94$ & $-867,34$ & $-357,22$ & $-823,37$ \\
\hline Saldo transferências (em R\$) & $20.144 .973,15$ & $11.201 .920,86$ & $36.046 .012,51$ & $67.392 .906,52$ \\
\hline $\begin{array}{l}\text { Saldo transferências por exposto } \\
\text { (em RS) }\end{array}$ & 155,27 & 22,96 & 223,76 & 86,54 \\
\hline Índice combinado (em \%) & 95,0 & 99,0 & 91,0 & 96,0 \\
\hline \multicolumn{5}{|l|}{ Razão receptores/doadores líquidos } \\
\hline Razão receita média & 1,95 & 2,70 & 2,38 & 2,63 \\
\hline Razão despesa média & 3,04 & 3,36 & 3,08 & 3,40 \\
\hline
\end{tabular}

Fonte: Amostra de operadoras de planos de saúde. Elaboração dos autores.

Nota: $\mathrm{RF}=$ resultado financeiro; $\mathrm{DA}=$ despesas administrativas; $\mathrm{DC}=$ despesas comerciais.

Considerando a distribuição etária em seu nível mais detalhado (idade simples), os valores de despesas excedem as receitas a partir dos 66 anos em todas as formas de contratação. Segundo os resultados, essa é a idade que define os grupos que são doadores 
e receptores líquidos de recursos, independentemente das faixas etárias utilizadas pela ANS. Enquanto a receita média dos receptores líquidos é 2 a 3 vezes superior à dos doadores líquidos, sua despesa média é 3 a 4 vezes maior, o que explica a necessidade de os mais velhos contarem com as transferências dos mais jovens. Em 2015, cada doador transferiu, em média, de 50 a 496 reais, dependendo do tipo de contratação. A variação depende não apenas do índice de sinistralidade, mas especialmente da relação entre o número de doadores e receptores líquidos, o que reforça a importância da estrutura etária. Conforme discutido na seção anterior, nos contratos coletivos empresariais, a distribuição etária reflete diretamente a estrutura do mercado de trabalho, havendo mais de 30 doadores por receptor, amenizando o valor da transferência por doador. Nos contratos individuais e coletivos por adesão, essa razão é bem menor, igual a 4,2 e 5,1 respectivamente. Considerando o esperado aumento da proporção de idosos e mantidas as atuais características dos planos, condições de precificações e alta sinistralidade, as receitas poderão se tornar insuficientes para cobertura das despesas no médio prazo.

\section{Transferências inter e intrageracionais segundo as faixas etárias da ANS}

Até aqui, a análise não se fixou nas dez faixas etárias definidas pela ANS, mas sim em uma distribuição por idade bastante detalhada, que permite medir com mais precisão as idades que definem doadores e receptores líquidos de recursos na saúde suplementar. Nessa seção estimamos o padrão de transferências considerando o padrão restritivo da ANS. A Tabela 3 apresenta o índice de sinistralidade e sua versão combinada, além do valor das transferências realizadas ou recebidas, considerando os resultados operacionais (mensalidades e despesas operacionais) e os resultados líquidos (todas as despesas e receitas), segundo as dez faixas etárias. Nota-se que os valores são positivos em todas as faixas etárias, no âmbito do resultado operacional. No entanto, ao considerar o resultado líquido, a faixa etária de 59 anos ou mais apresentou saldo negativo. Obviamente, como são apenas dez faixas de idade, as transferências intergeracionais são reduzidas, comparativamente à análise com idade simples, e na prática são substituídas por transferências intrageracionais. Como a regulamentação brasileira determina que sejam praticadas mensalidades uniformes para beneficiários de uma mesma faixa etária, independentemente das diferenciações de risco e, portanto, de despesas, essa é uma das principais consequências do sistema de precificação da ANS.

Especificamente duas faixas etárias ( 0 a 18 anos e 59 anos ou mais) contemplam ampla gama de indivíduos com significativa heterogeneidade de idade e risco, o que implica transferências de recursos entre os indivíduos de baixo e alto risco dentro de cada faixa etária, como fica evidente pelos dois painéis apresentados no Gráfico 4. No caso da faixa etária 0 a 18 anos, o saldo das transferências é negativo até a idade de um ano (com ligeira variação entre o resultado operacional e o líquido), tornando-se positivo a partir de 
então, o que significa que pessoas com idades de 1 a 18 anos pagam mensalidades com valor superior às suas despesas (saldo de $\mathrm{R} \$ 72,9$ milhões no âmbito operacional), mais do que contrabalançando o resultado negativo das crianças com menos de um ano (R\$ 12,4 milhões no âmbito operacional). No caso da faixa etária mais velha, 59 anos e mais, verifica-se que até os 65 anos os valores totais de receita são superiores à soma de todas as despesas; relação que se inverte a partir dessa idade. No entanto, diferentemente dos mais jovens, as transferências intrageracionais são insuficientes para o financiamento das despesas de toda a faixa etária 59 anos e mais. Em consonância com a análise anterior, realizada por idade simples, indivíduos acima de 66 anos necessitam não apenas de transferências de pessoas de 59 a 65 anos, mas também daquelas realizadas por adultos de faixas etárias mais jovens.

TABELA 3

Transferências intergeracionais, segundo faixas etárias ANS - 2015

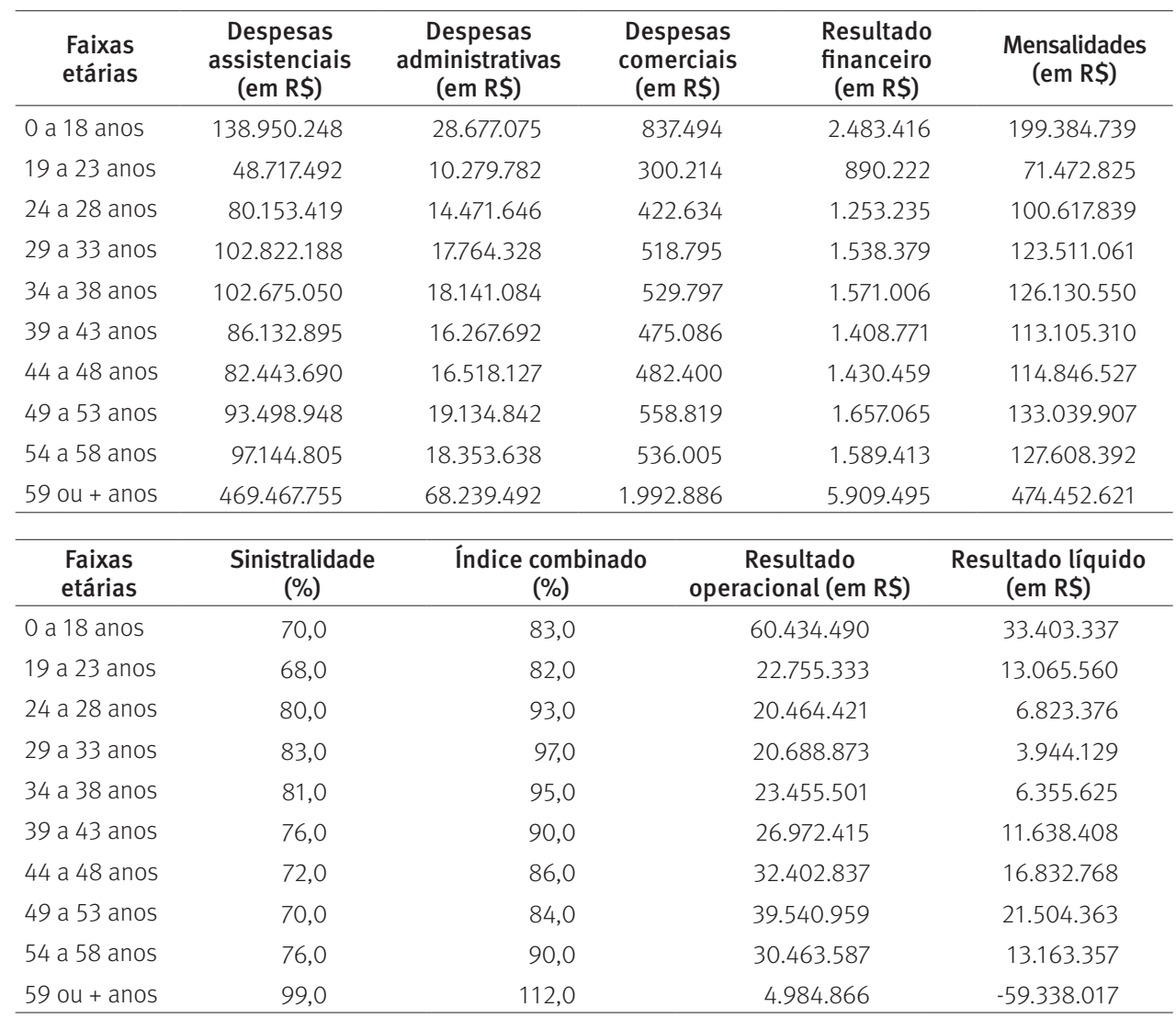

Fonte: Amostra de operadoras de planos de saúde. Elaboração dos autores. 


\section{GRÁFICO 4}

Transferências intrageracionais, segundo faixas-etárias da ANS - 2015
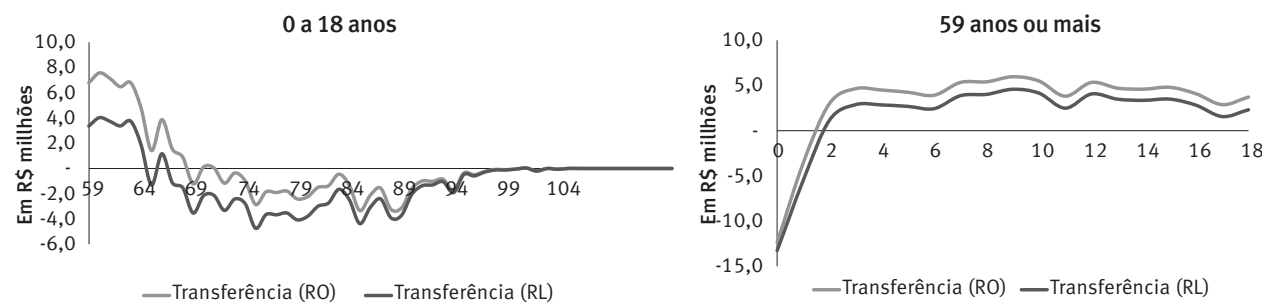

Fonte: Amostra de operadoras de planos de saúde. Elaboração dos autores.

\section{Retroprojeção das transferências intergeracionais}

Os saldos das transferências examinados em seção anterior demonstram que, embora o pacto intergeracional tenha se apresentado positivo em todos os tipos de contratação, a margem percentual da diferença entre as receitas e despesas é significativamente baixa. Vale examinar, portanto, a sensibilidade da sinistralidade em relação às variações na estrutura etária dos beneficiários, por tipo de contratação. Para isso consideraram-se as distribuições etárias da amostra no período de 2000 a 2015, por idade simples, e os valores médios de mensalidades e despesas assistenciais observados em 2015, ou seja, apenas o resultado de natureza operacional, sem incluir as despesas administrativas, comerciais e as receitas provenientes de resultado financeiro.

Estima-se um aumento de um ponto percentual na sinistralidade de todos os planos de saúde considerados na amostra desde 2000, em função das mudanças na estrutura etária no período de 15 anos. Analisando os resultados segundo o tipo de contratação, constata-se que o impacto é significativamente maior nos planos de contratação individual, que apresentaram variação de oito pontos percentuais no indicador de sinistralidade, comparado a um ponto percentual nos planos coletivos empresariais e coletivos por adesão (Gráfico 5).

GRÁFICO 5

Índices de sinistralidade, por tipo de contratação - 2000-2015

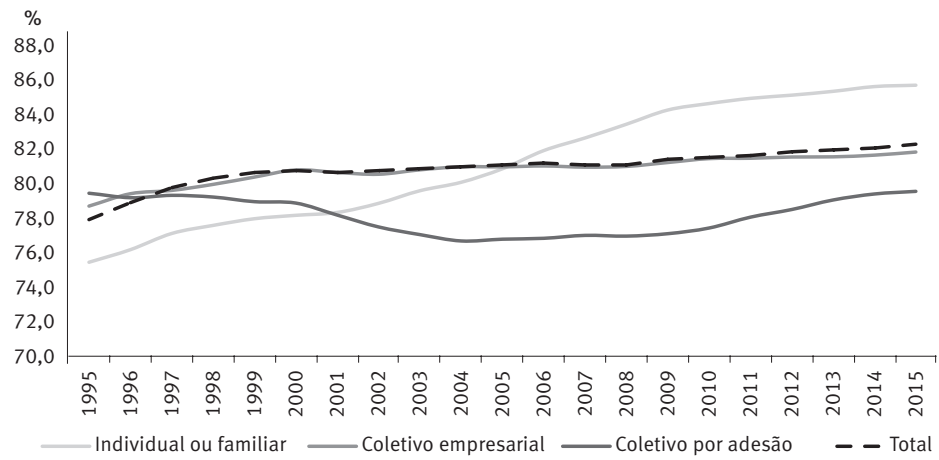




\section{Discussão}

Esse artigo teve como objetivo estimar a magnitude das transferências intergeracionais e intrageracionais em uma amostra de 11 OPS no Brasil. Os resultados obtidos representam um avanço em relação à literatura empírica nacional. Turra et al. (2015), com base em uma subamostra de 16 OPS, já haviam mensurado a magnitude dessas transferências para o país. No entanto, devido à indisponibilidade das informações por idade simples, as estimativas se restringiram às transferências líquidas entre faixas etárias decenais. Além disso, os autores não consideraram nas estimativas as receitas financeiras e as despesas operacionais e administrativas.

O desenvolvimento desse tipo de análise é particularmente relevante para o país, tendo em vista o contexto de envelhecimento populacional e o papel que as seguradoras exercem no sistema de saúde brasileiro. A importância das OPS, tanto no provimento quanto no financiamento desses serviços, vem crescendo gradativamente desde a Constituição Federal de 1988 , cobrindo, atualmente, aproximadamente $25 \%$ da população brasileira (ANS, 2018a). A regulamentação do setor de planos e seguros privados de saúde aumentou desde então, inicialmente com a Lei n. 9.656 de 1998, que estabeleceu algumas medidas sobre a operação dos planos de forma a proteger os consumidores. A Agência Nacional de Saúde Suplementar (ANS), vinculada ao Ministério da Saúde, foi criada em 2000, a partir da Lei n. 9.961, e ampliou a defesa do interesse público no provimento de assistência suplementar à saúde (ANS, 2001). Uma das regras mais importantes, prevista na Resolução Normativa n. 63/03, diz respeito aos mecanismos de regulação dos preços segundo faixas de idade, especialmente entre os grupos etários extremos. A extensão em que essa regra gera um subsídio intergeracional depende em que medida a razão dos gastos entre esses dois grupos supera o limite de precificação imposto pela ANS às OPS.

Os resultados encontrados no presente artigo mostram que o desempenho líquido das OPS amostradas é positivo. A sinistralidade média, calculada a partir da razão entre as despesas assistenciais e receitas provenientes das mensalidades, correspondeu a $82 \%$, em 2015. Apesar de positivo, o índice de sinistralidade mostra que as OPS podem estar operando com um resultado crítico, na medida em que se recomenda que esse índice fique abaixo de 70\%-75\% (CASTRO NETI; DE OLIVEIRA, 2012; SILVA; LOEBEL, 2016). Quando consideradas as despesas administrativas e comerciais e as receitas financeiras no cálculo do índice de sinistralidade, o resultado para a média dessas operadoras é de $96 \%$, implicando uma margem de lucro de apenas $4 \%$. Esse percentual varia segundo o tipo de contratação, sendo $91 \%$ para os planos coletivos por adesão, $95 \%$ para os individuais e $99 \%$ para os coletivos empresariais.

A análise do comportamento das despesas e receitas totais por idade permite mensurar as transferências intergeracionais e avaliar em que medida os resultados positivos gerados atualmente pelas OPS amostradas é sustentado pela presença de subsídios cruzados. Considerando conjuntamente todos os tipos de contrato, os grupos etários que estariam 
sendo subsidiados (receptores líquidos) seriam aqueles com 66 anos ou mais. Em 2015, cada beneficiário desse grupo "recebeu”, em média, um subsídio intergeracional na ordem de $\mathrm{R} \$ 823,37$. Tendo em vista que a transferência média de cada doador (com idade entre 0 e 65 anos) era de $R \$ 170,41$, seriam necessários cerca de cinco beneficiários do grupo de doadores para financiar o gasto excedente de cada beneficiário receptor. 0 resultado positivo das OPS é explicado pela maior quantidade de beneficiários no grupo etário com menos de 66 anos, que supera em quase 11 vezes o total daqueles com 66 anos e mais. Analisando separadamente os contratos dos planos individuais e coletivos empresariais, observa-se que há, respectivamente, em torno de 4 e 32 beneficiários com menos de 66 anos para cada beneficiário do grupo de idade mais avançada. Esse valor supera em $65 \%$ e $88 \%$ a quantidade necessária de doadores para garantir a saúde financeira das OPS, respectivamente para os dois tipos de contratação.

Além das transferências intergeracionais, foram também avaliadas as transferências intrageracionais. Essa estimativa é importante uma vez que as faixas de idade estabelecidas pela RN 63/03 são amplas, especialmente as extremas, o que pode gerar uma heterogeneidade muito grande no padrão de morbidade e, consequentemente, nos gastos com saúde. Como esperado, essas transferências ocorreram nos grupos de maior amplitude (0 a 18 e 59 anos ou mais). No entanto, apenas na faixa etária de 59 anos ou mais foi observado um saldo líquido negativo, sendo, portanto, necessárias receitas provenientes de outras faixas etárias para suprir os gastos dos beneficiários deste grupo.

As estimativas da retroprojeção da sinistralidade mostram o quão sensível estaria a saúde financeira das OPS amostradas em relação às mudanças na estrutura etária dos beneficiários. De acordo com os resultados, alterações na estrutura etária observadas entre 2000 e 2015 acarretariam um aumento de um ponto percentual na sinistralidade. Considerando apenas os planos de contratos individuais, essa variação seria de oito pontos percentuais, enquanto nos planos coletivos empresariais corresponderia a menos de um ponto percentual. Esses resultados, embora refiram-se a um período bastante curto do ponto de vista demográfico (15 anos), sugerem que futuras mudanças na estrutura populacional afetarão as margens operacionais das OPS em todos os tipos de contratação, o que causará pressão sobre o pacto intergeracional com consequências para as regras de precificação e para os tipos de serviços oferecidos. É importante considerar que as despesas assistenciais não aumentam apenas em função das alterações da estrutura etária, existindo outros fatores não considerados nesse estudo, tais como as inovações tecnológicas, que podem contribuir para a acelerada variação dos custos médico-hospitalares.

Os resultados obtidos neste artigo sugerem que, considerando a atual estrutura etária dos beneficiários, é possível observar um desempenho positivo das OPS analisadas. No entanto, a manutenção desse pacto pode estar fragilizada na medida em que a margem percentual da diferença entre as receitas e despesas é baixa. Nas fases iniciais do processo de transição demográfica, quando o ritmo de crescimento populacional é alto e a participação relativa de jovens na população é ainda elevada, as transferências são diluídas entre 
uma grande população de jovens e o pacto intergeracional torna-se um instrumento de financiamento minimamente sustentável. Com o avanço desse processo e o envelhecimento populacional em estágio mais avançado, há um aumento na necessidade de transferências líquidas dos jovens para idosos. Como resultado, o pacto de solidariedade entre as gerações e, consequentemente, a sustentabilidade financeira das OPS são colocados em xeque (TURRA et al., 2015). Essa situação é especialmente relevante para os planos de contratos individuais que já apresentam uma carteira relativamente mais envelhecida em comparação aos coletivos empresariais. 0 teto de reajuste anual desses contratos é definido pela ANS, ao contrário dos contratos coletivos empresariais e coletivos por adesão, que não são submetidos a essa regulação (ANS, 2018b). Além disso, os planos individuais não podem ser restringidos unilateralmente e, portanto, as operadoras não podem cancelar 0 contrato caso este deixe de ser vantajoso, a não ser que tal desejo parta dos beneficiários. Nesse contexto, nos últimos anos, muitas operadoras têm restringido a oferta de planos individuais (IDEC, 2013).

Visto que o pacto intergeracional pode não se sustentar diante das condições atuais previstas na regulamentação vigente, principalmente na contratação individual, algumas ações devem ser tomadas a fim de manter a capacidade financeira do setor de saúde suplementar. 0 ajuste das mensalidades por outros fatores de riscos observáveis de cada indivíduo não é uma alternativa a ser colocada em pauta. Além de proibida pela ANS, essa prática pode ser considerada injusta, principalmente se as diferenças nos valores cobrados das mensalidades entre os grupos de risco forem muito altas, podendo até mesmo excluir indivíduos com piores condições de saúde. Em geral, as medidas regulatórias adotadas em diferentes sociedades têm como objetivo garantir acesso equitativo aos seguros de saúde independentemente do nível de risco e das condições socioeconômicas dos indivíduos. Dessa forma, a adoção da precificação baseada no community rating tem sido recorrentemente adotada. Esse é o caso, por exemplo, da Austrália, Bélgica e Holanda (SOWA et al., 2018; SCHILLAERT et al., 2018; VAN KLEEF et al., 2018). Esse tipo de precificação, em que nenhuma variável de risco é utilizada para ajustar o valor dos prêmios cobrados, pode gerar problemas associados à seleção adversa (VAN DE VEN; ELLIS, 2000). Mesmo no Brasil, onde a regulação permite que os preços das mensalidades variem segundo grupos de idade, a seleção adversa pode ser observada, uma vez que esse atributo não absorve todo o risco associado aos gastos esperados. Apesar da correlação entre idade e gastos de saúde, há um intenso debate na literatura sobre a natureza desta relação. Argumenta-se que a idade é apenas uma proxy, isto é, uma variável que substitui outras características observáveis ou não observáveis que podem afetar indiretamente os gastos de saúde, como, por exemplo, tempo até a morte, padrão de morbidade e preço e qualidade da tecnologia médica disponível (RAITANO, 2006; MILLER, 2001; MAIA; ANDRADE; FERES, 2012; RODRIGUES; AFONSO, 2012). Além disso, as regras regulatórias podem limitar a razão pela qual os prêmios de risco poderão variar entre esses subgrupos. Outros países, como Suíça e Alemanha, também ajustam os prêmios por alguns fatores de risco. Na Suiça, o ajuste dos prêmios de seguro 
é realizado por grupos de idade e região (VAN DE VEN et al., 2003; OECD, 2004; LEU et al., 2009). Na Alemanha, os valores dos prêmios podem variar dependendo do sexo, idade e condição física. Mas essa diferenciação ocorre apenas no momento da adesão, não podendo sofrer ajustes posteriores de acordo com a idade (MENDES, 2009).

No modelo atual de compartilhamento parcial de risco com base na idade, a preocupação no Brasil com os efeitos da transição demográfica é justificada, principalmente considerando a redução na oferta de beneficiários mais jovens. A população brasileira está envelhecendo de forma persistente (CARVALHO et al., 1998; BRITO et al., 2007) e dificilmente esse processo será revertido. Adicionalmente, mesmo que futuramente o país se torne economicamente atraente para jovens migrantes internacionais, esses fluxos migratórios não irão contribuir para um rejuvenescimento permanente da população. Nesse sentido, a realidade que será vivenciada pelo país ao longo deste século será de uma população em constante envelhecimento (TURRA, 2018).

Alguns mecanismos podem ser adotados de forma a garantir a sustentabilidade das OPS, mantendo a estratégia de subsídio cruzado no contexto de uma população mais envelhecida. Dentre os mecanismos comumente observados em diferentes sociedades, destacam-se os incentivos para cobertura vitalícia (life-time health cover), fundo de envelhecimento e incentivos fiscais para cobertura privada (MENDES, 2009; BAUMANN et al., 2004; PAOLUCCI; SHMUELI, 2011; PAOLUCCI; STOELWINDER, 2011). A forma como os mecanismos são implementados e suas implicações dependem das especificidades das políticas e dos sistemas de saúde de cada país. Na Austrália, por exemplo, são concedidos subsídios para indivíduos com cobertura privada, enquanto impostos são aplicados àqueles com renda mais elevada, mas sem plano de saúde. Neste país, indivíduos são também estimulados a terem cobertura privada de saúde vitalícia para garantir maior diversificação do risco nas carteiras de segurados (MENDES, 2009). Na Alemanha, foi criado um fundo de envelhecimento no setor de planos privados de saúde, em que são cobrados $10 \%$ sobre o valor total do prêmio quando os indivíduos têm entre 21 e 60 anos de idade. Tal valor é anualmente adicionado neste fundo de envelhecimento, que pode ser utilizado quando os indivíduos completam 65 anos de idade, de forma a reduzir o valor dos prêmios cobrados (MENDES, 2009; BAUMANN et al., 2004).

Singapura, China, África do Sul e Estados Unidos têm adotado uma forma alternativa de financiamento do sistema de saúde, o Medical Savings Accounts (MSA), que consiste na realização de poupanças individuais ou familiares para financiar os gastos com serviços de saúde realizados ao longo do ciclo de vida (LANGE; STEINORTH, 2012; HANVORAVONGCHAI, 2002). Esse modelo oferece uma alternativa de proteção aos beneficiários em relação a prováveis aumentos futuros nos valores dos prêmios em razão do envelhecimento populacional. Seu sucesso no Brasil dependeria, dentre outros fatores, do grau de adesão dos grupos etários mais jovens, uma vez que o modelo atual, baseado no mutualismo, não deixaria de existir. Dessa forma, os serviços de saúde das coortes atuais de idosos teriam que continuar a ser financiados, independentemente do esforço de poupança realizado pelos jovens. 
No contexto brasileiro, há outros aspectos importantes que devem ser considerados para implementação de ações que visam à sustentabilidade do setor de planos e seguros privados. 0 primeiro aspecto a ser levado em conta e que deverá pautar as medidas que venham a ser adotadas refere-se ao desenho do sistema de saúde brasileiro. 0 sistema é caracterizado como misto, coexistindo os setores público e privado no financiamento e provimento desses serviços. No sistema público de saúde (Sistema Único de Saúde - SUS), a oferta é integral, universal e gratuita. 0 setor privado tem um papel duplicativo na medida em que pode ofertar os mesmos serviços que o sistema público. Segundo Andrade et al. (2018), este arcabouço institucional afeta de forma diferenciada a demanda pelos serviços de saúde no SUS e no setor privado. Os indivíduos que possuem cobertura privada de saúde podem ter incentivos a utilizar o SUS diante da restrição da oferta desses serviços pelas OPS ou da presença de mecanismos de divisão de custos muito elevados que comprometam o orçamento familiar. Além disso, para determinados tipos de cuidados, a qualidade dos serviços prestados pelo SUS é reconhecidamente melhor do que do setor privado. Essas situações são especialmente válidas para os serviços de maior complexidade, cujos custos são muito elevados. Dessa forma, é possível que o impacto do envelhecimento populacional venha a ter implicações mais fortes sobre a sustentabilidade financeira das carteiras de segurados, principalmente, diante da obrigatoriedade do setor privado de arcar integralmente com os custos do cuidado ofertado pelo setor público aos seus beneficiários. 0 ressarcimento ao SUS já é uma realidade para procedimentos que estão previstos nos contratos ou no rol de procedimentos definidos pela ANS. Mas ainda são necessários a adoção de mecanismos mais eficazes de controle e o aperfeiçoamento contínuo para sua efetiva implementação. Além disso, se houver um agravamento do subfinanciamento historicamente observado no SUS, a oferta desses serviços pelo setor público pode ser comprometida, dificultando o acesso aos serviços de saúde, sobretudo os de maior complexidade.

0 segundo aspecto refere-se à necessidade de melhorar a gestão das despesas assistenciais. Parte do aumento dos gastos assistenciais nos últimos anos pode ser atribuída a desperdícios decorrentes do excesso de procedimentos e incorporação de tecnologias que não atendem aos critérios de custo-efetividade, que são induzidos pela estrutura de pagamento atual (COUTO et al., 2016). Alguns autores afirmam que o mercado privado de serviços médicos pode ser visto como estímulo para avanços tecnológicos, uma vez que fornecem garantia aos médicos e prestadores de serviços de que os usuários terão recursos para arcar com os procedimentos, incentivando a pesquisa e resultando em criação de novas tecnologias. Dessa forma, o sistema de financiamento da saúde suplementar gera um risco moral dinâmico, com incentivos para uma posterior implementação de tecnologias (ANDRADE, 2003; GOYEN; DEBATIN, 2009; AZEVEDO et al., 2016). Além disso, o modelo de remuneração mais comumente aplicado no Brasil é o fee for service, em que as operadoras efetuam o pagamento por atendimento, de forma que quanto mais caro forem os procedimentos realizados, maior será o ganho dos prestadores (ANDRADE, 2003; AZEVEDO et al., 2016). 
Outra medida importante para a gestão das despesas assistenciais é a aplicação e incentivo da medicina preventiva ao longo do ciclo de vida dos indivíduos. Os seus efeitos são de longo prazo, mas têm sido uma das propostas para reduzir o impacto do envelhecimento populacional nos gastos com saúde, pois podem postergar o surgimento e as consequências adversas das doenças (FAUSTO; MATTA, 2007; CZERESNIA, 2003). A prevenção pode ainda trazer resultados satisfatórios em relação à longevidade dos indivíduos, implicando redução das despesas assistenciais per capita, uma vez que a longevidade pode resultar em menores despesas no momento da morte (MILLER, 2001; LUBITZ; RILEY, 1993; SESHAMANI; GRAY, 2004). Algumas iniciativas têm sido implementadas no mercado de seguros e planos privados de saúde no Brasil, como, por exemplo, os programas de promoção da saúde e prevenção de riscos e doenças, que têm sido estimulados pela ANS desde 2004 (ANS, 2011).

Finalmente, ressalta-se que a transição demográfica, com o consequente aumento na proporção de pessoas nas idades mais avançadas, coloca em pauta a discussão sobre a própria definição de idoso. Ganhos de longevidade em geral vêm acompanhados de melhorias na qualidade de vida e desenvolvimento econômico. Dessa forma, espera-se que os idosos experimentem, cada vez mais, melhores condições de saúde, aumentando sua inserção no mercado de trabalho e sua capacidade de geração de renda. Nesse contexto, será imprescindivel uma discussão mais ampla sobre a definição de idosos no país, que atualmente considera indivíduos com idade igual ou superior a 60 anos. Convencionalmente, em países com níveis mais avançados de envelhecimento populacional, a definição de idoso considera a idade cronológica de 65 anos, embora já haja propostas para sua elevação (SANDERSON; SHERBOV, 2013; OUCHI et al., 2017). Essa discussão gera a necessidade de revisar o Estatuto do Idoso, que impede qualquer prática discriminatória entre indivíduos acima de 60 anos. Será fundamental reconhecer a heterogeneidade de riscos existente em um grupo tão amplo quanto o formado por indivíduos de 60 anos e mais, bem como a possibilidade de mudanças nestes riscos ao longo do tempo (TURRA et al., 2015).

\section{Referências}

ALVES, S. L. Estimando seleção adversa em planos de saúde. EconomiA - Selecta, Brasília, v. 5 , n. 3, p. 253-283, dez. 2004

ANDRADE, M. V. Financiamento do setor de saúde suplementar no Brasil: uma investigação empírica a partir dos dados da PNAD/1998. In: WERNECK, A. J.; MONTONE J. (Org.). Regulação e saúde: documentos técnicos de apoio ao Fórum de Saúde Suplementar de 2003. 1. ed. Rio de Janeiro: Ministério da Saúde/Agência Nacional de Saúde Suplementar, v. 3, 2003. p. 249-332.

ANDRADE, M. V. et al. Indicadores de gastos com serviços médicos no setor de saúde suplementar no Brasil: o caso Sabesprev. Belo Horizonte: Cedeplar/Face/UFMG, 2010 (Texto para discussão, 403).

ANDRADE, M. V.; NORONHA, K.; SA, E. B.; PIOLA, S.; VIEIRA, F. S.; VIEIRA, R. S.; BENEVIDES, R. Desafios do sistema de saúde brasileiro. In: NEGRI, J. A. de; ARAÚJO, B. C.; BACELETTE, R. (Org.). Desafios da nação: artigos de apoio. 1. ed. Brasília: Ipea, 2018. v. 2, p. 357-414. 
ANS - Agência Nacional de Saúde Suplementar. Integração do setor de saúde suplementar ao sistema de saúde brasileiro (3 anos da Lei 9.656). Palestra proferida no Conselho Nacional de Saúde. Rio de Janeiro, jul. 2001 Janeiro, 2011.

RN Promoção da Saúde e Prevenção de Riscos e Doenças. Nota técnica. Rio de

Anuário - Aspectos econômico-financeiros das operadoras de planos de saúde. Rio de Janeiro, 2015.

Dados consolidados saúde suplementar. Rio de Janeiro: Agência Nacional de Saúde, 2018 a.

Reajustes de preços de planos de saúde. Agência Nacional de Saúde, 2018b. Disponível em: 〈http://www.ans.gov.br/planos-de-saude-e-operadoras/espaco-do-consumidor/ reajustes-de-precos-de-planos-de-saude>. Acesso em: 10 set. /2018.

Resolução da Diretoria Colegiada RDC n. 28, de 26 de junho de 2000. Rio deJaneiro, 2000. Disponivel em: 〈http://www.ans.gov.br/component/legislacao/?view=legislacao \&task=TextoLei\&format=raw\&id=Mzg3〉.

Resolução Normativa n. 63, de 22 de dezembro de 2003. Rio d Janeiro, 2003.Disponivel em: 〈http://www.ans.gov.br/component/legislacao/?view=legislacao \&task=TextoLei\&format=raw\&id=NzQ4>.

AZEVEDO, P. F. et al. A cadeia de saúde suplementar no Brasil: avaliação de falhas de mercado e propostas de políticas. São Paulo: Insper - Centro de Estudos em Negócios, 2016 (White Paper, n. 001).

BAUMANN, F.; MEIER, V.; WERDING, M. Transferable ageing provisions in individual health insurance contracts. CESifo Group Munich, 2004 (CESifo Working Paper, n. 1116).

BERENSTEIN, C. K. O perfil etário dos custos de internação na saúde pública no Brasil: uma análise para as capitais das regiões metropolitanas do Brasil em 2000. Dissertação (Mestrado em Demografia) - Centro de Desenvolvimento e Planejamento Regional, Universidade Federal de Minas Gerais (Cedeplar/UFMG), 2005.

BRITO et al. A transição demográfica e as políticas públicas no Brasil: crescimento demográfico, transição da estrutura etária e migrações internacionais. Belo Horizonte, 2007.

CARVALHO, J. A M de. Crescimento populacional e estrutura demográfica no Brasil. Belo Horizonte: Centro de Desenvolvimento e Planejamento Regional, Universidade Federal de Minas Gerais (Cedeplar/UFMG), 2004 (Texto para Discussão, n. 227).

CARVALHO, J. A M. de; GARCIA, R. A. O envelhecimento da população brasileira: um enforque demográfico. Cadernos de Saúde Pública, v. 19, n. 3, p. 725-733, 2003.

CARVALHO, J. A M. de; SAWYER, D. O.; RODRIGUES, R. D. Introdução a alguns conceitos básicos e medidas em demografia. 2. ed. São Paulo: Associação Brasileira de Estudos Populacionais, 1998.

CASTRO NETO, F. C.; DE OLIVEIRA, J. C. C. Saúde suplementar no Brasil: estudo sobre as correlações de índices econômico-financeiros das operadoras de planos de saúde. Revista Diálogos Acadêmicos, v. 1, n. 2, p. 138-149, 2012.

COUTO, R. C.; PEDROSA, T. G. M.; ROSA, M. B. Erros acontecem: a força da transparência dos eventos adversos assistenciais em pacientes hospitalizados. Belo Horizonte: IESS - Instituto de Estudos de Saúde Suplementar, 2016.

CUTLER, D. M.; MEARA, E. The medical costs of the young and old: a forty year perspective. In: 
WISE, D. A. (Ed.). Frontiers in the economics of aging. Chicago, IL: University of Chicago Press, 1998. p. 215-246.

CZERESNIA, D. Ações de promoção à saúde e prevenção de doenças: o papel da ANS. In: WERNECK, A. J.; MONTONE J. (Org.). Regulação e saúde: documentos técnicos de apoio ao Forúm de Saúde Suplementar de 2003. 1. ed. Rio de Janeiro: Ministério da Saúde/Agência Nacional de Saúde Suplementar, v. 3, 2003.

FAUSTO, M. C. R.; MATTA, G. C. Atenção primária à saúde: histórico e perspectivas. Modelos de atenção e a saúde da família. Rio de Janeiro: Fiocruz, 2007.

FIPECAFI. Diferenciação de risco e mensalidade ou prêmio entre faixas etárias em planos e seguros de saúde. Parecer técnico: São Paulo, 2009.

GABRIELE, S. et al. Demographic factors and health expenditure profiles by age: the case of Italy. European Network of Economic Policy Research Institutes, 2005 (ENEPRI Research Report, n. 18).

GOYEN, M.; DEBATIN, J. F. Healthcare costs for new technologies. European Journal of Nuclear Medicine and Molecular Imaging, v. 36, suppl. 1, p. 139-143, 2009.

HANVORAVONGCHAI, P. Medical savings accounts: lessons learned from limited international experience. Geneva: World Health Organizations,2002

IBGE - Instituto Brasileiro de Geografia e Estatística. Projeção da população do Brasil por sexo e idade: 2000-2060 - Revisão 2013. Rio de Janeiro, 2013.

IDEC - Instituto Brasileiro de Defesa do Consumidor. Saúde não é o que interessa. Revista do IDEC, edição 177, p. 21-24, jun. 2013.

KEEHAN, S. et al. Age estimates in the national health accounts. Heath Care Financing Review, v. 26, n. 2, p. 1-16, 2004.

KILSZTAJN et al. Serviços de saúde, gastos e envelhecimento da população brasileira. In: XIII ENCONTRO NACIONAL DE ESTUDOS POPULACIONAIS. Anais... Ouro Preto: Abep, 2002.

LANGE, R.; STEINORTH, P. Using experiences from the U.S. to implement health savings accounts in German statutory health insurance. Schmollers Jahrbuch, v. 132, n. 1, p. 27-52, 2012.

LEU, R. E.; RUTTEN, F. F. H.; BROUWER, W.; MATTER, P.; RÜTSCHI, C. The Swiss and Dutch health insurance systems: universal coverage and regulated competitive insurance markets. New York: The Commonwealth Fund, pub. n. 1220, 2009.

LUBITZ, J.; RILEY, G. F. Trends in medicare payments in the last year of life. New England Journal of Medicine, v. 328, n. 15, p. 1092-1096, 1993.

MAIA, A. C. Seleção adversa e risco moral no sistema de saúde brasileiro. Dissertação (Mestrado) - Centro de Desenvolvimento e Planejamento Regional (Cedeplar), Universidade Federal de Minas Gerais (UFMG), Belo Horizonte, 2004.

. Ensaios sobre a demanda no setor de saúde suplementar brasileiro. Tese (Doutorado em Economia) - Centro de Desenvolvimento e Planejamento Regional (Cedeplar), Universidade Federal de Minas Gerais (UFMG), Belo Horizonte, 2012.

MAIA, A. C.; ANDRADE, M. V.; FERES, F. L. C. Estudo longitudinal do efeito da idade e tempo até a morte em gastos com saúde. Rede de Economia Aplicada (Reap), 2012 (Working Paper 037).

MAIA, A. C.; ANDRADE, M. V.; OLIVEIRA, A. M. O risco moral no sistema de saúde suplementar brasileiro. In: XXXII ENCONTRO NACIONAL DE ECONOMIA. Anais... João Pessoa: Anpec, 2004.

MENDES, J. Seguros de saúde vitalícios: estudo de práticas e direito comparado. Fórum -Lisboa, ano XIII, n. 27, p. 44-71, jul. 2009. 
MILLER, T. Increasing longevity and medicare expenditures. Demography, v. 38, n. 2, p. 215-226, 2001.

MYRRHA, L. J. Estrutura etária brasileira: decomposição segundo variações na fecundidade e na mortalidade. Dissertação (Mestrado) - Centro de Desenvolvimento e Planejamento Regional (Cedeplar), Universidade Federal de Minas Gerais (UFMG), Belo Horizonte, 2009.

MYRRHA, L. J.; SIVIERO, P. C.; WAJNMAN, S.; TURRA, C. M. O uso das taxas de crescimento por idade para identificação das principais etapas da transição demográfica no Brasil. Belo Horizonte: Centro de Desenvolvimento e Planejamento Regional (Cedeplar), Universidade Federal de Minas Gerais (UFMG), 2012 (Texto para Discussão, n. 460).

A contribuição dos nascimentos e óbitos para o envelhecimento populacional no Brasil, 1950 a 2100. Revista Latino-Americana de Población, ano 11, n. 20, p. 37-54, 2017.

NUNES, A.; SOARES, F. A. R.; BASÍLIO, F. A. C. A regulação do mercado de saúde e os efeitos sobre a seleção adversa. Revista de Economia, v. 40, n. 2, p. 23-38, 2014.

OECD - Organisation for Economic Co-operation and Development. Private health insurance in OECD countries. Policy Brief, September 2004

OMRAN, A. R. The epidemiologic transition: a theory of the epidemiology of population change. Milbank Memorial Fund Quaterly, v. 49, n. 4, p. 509-538, 1971.

OUCHI, Y. et al. Redefining the elderly as aged 75 years and older: proposal from the Joint Committee of Japan Gerontological Society and the Japan Geriatrics Society. Geriatrics Gerontology, v. 17, n. 7, p. 1045-1047, 2017.

PAOLUCCI. F.; SHMUELI, A. The introduction of ex-ante risk equalisation in the Australian private health insurance market: a first step. Agenda, v. 18, n. 2, p. 71-92, 2011.

PAOLUCCI, F.; STOELWINDER, J. Risk-equalisation in health insurance markets: models and international experience. Melbourne: Australian Centre for Health Research, Feb. 2011.

RAITANO, M. The impact of death-related costs on health-care expenditure: a survey. ENEPRI Research Report, n. 17, 2006.

REIS, C. S.; NORONHA, K.; WAJNMAN, S. Envelhecimento populacional e gastos com internação do SUS: uma análise realizada para o Brasil entre 2000 e 2010. Revista Brasileira de Estudos de População, v. 33, n. 3, p. 591-612, 2016.

RESENDE, M.; ZEIDAN, R. Adverse selection in the health insurance market: some empirical evidence. The European Journal of Health Economics, v. 11, n. 4, p. 413-418, 2010.

RIBEIRO, M. M. Utilização de serviços de saúde no Brasil: uma investigação do padrão etário por sexo e cobertura por plano de saúde. Dissertação (Mestrado) - Centro de Desenvolvimento e Planejamento Regional (Cedeplar), Universidade Federal de Minas Gerais (UFMG), Belo Horizonte, 2005.

RICHARDSON, J.; ROBERTSON, L. Ageing and the cost of health services. West Heidelberg, Australia: Centre for Health Program Evaluation, 1999 (Working Paper, n. 90).

RODRIGUES, C. G.; AFONSO, L. E. O efeito do status de sobrevivência sobre gastos com internações hospitalares públicas no Brasil em uma perspectiva temporal. Estudos Econômicos, v. 42, n. 3, p. 489-510, 2012.

SANDERSON, W. C.; SCHERBOV, S. The characteristics approach to the measurement of population aging. Population and Development Review, v. 39, n. 4, p. 673-685, 2013.

SCHILLAERT, E.; GUILLAUME, J.; VAN DE VOORDE, C. Risk adjustment in Belgium: why and how to 
introduce socioeconomic variables in health plan payment. In: MACGUIRE, T. G.; VAN KLEEF, R. C. Risk adjustment, risk sharing and premium regulation in health insurance markets. London: Academic Press, 2018. p. 209-234.

SESHAMANI, M.; GRAY, A. M. Time to death expenditure: an improved model for the impact of demographic change on health care costs. Age and Ageing, v. 33, n. 6, p. 556-561, 2004.

SILVA, V. V.; LOEBEL, E. Desempenho econômico-financeiro de operadoras de planos de saúde suplementar. Revista de Gestão em Sistemas de Saúde - RGSS, v. 5. n. 2, p. 57-70, jul./dez 2016.

SOWA, P. M. et al. Private health insurance incentives in Australia: in search of cost-effective adjustments. Appl Health Econ Health Policy, v. 16, n. 1, p. 31-41, 2018.

TURRA, C. M. Os ajustes inevitáveis da transição demográfica no Brasil. In: ANDRADE, M.V.; ALBUQUERQUE, E. M. (Org.). Alternativas para uma crise de múltiplas dimensões. Belo Horizonte: Cedeplar/UFMG, 2018.

TURRA, C. M.; NORONHA, K.; ANDRADE, M. V. Estimativa do Pacto Intergeracional e seu efeito na capacidade de financiamento das OPS. Relatório final. Belo Horizonte: Ipead/Cedeplar/ UFMG, 2015.

VAN DE VEN, W. P. M. M.; ELLIS, R. Risk adjustment in competitive health plan markets. In: NEWHOUSE; J. P.; CULYER, A. J. (Ed.). Handbook of health economics. Amsterdam: North-Holland, 2000.

VAN DE VEN et al. Risk adjustment and risk selection on the sickness fund insurance market in five European countries. Health Policy, v. 65, n. 1, p. 75-98, 2003.

VAN KLEEF, R. C.; EIJKENAAR, F.; VAN VLIET, R. C.; VAN DE VEN, W. P. Health plan payment in the Netherlands. In: MACGUIRE, T. G.; VAN KLEEF, R. C. Risk adjustment, risk sharing and premium regulation in health insurance markets. London: Academic Press, 2018. p. 397-429.

\title{
Sobre os autores
}

Samara Lauar Santos é mestre em Demografia pelo Centro de Desenvolvimento e Planejamento Regional (Cedeplar) da Universidade Federal de Minas Gerais (UFMG). Professora substituta do Departamento de Finanças e Contabilidade (DFC) da Universidade Federal da Paraíba (UFPB).

Cássio M. Turra é doutor em Demografia pela Universidade da Pensilvânia. Professor associado da Faculdade de Ciências Econômicas (Face), Departamento de Demografia, da Universidade Federal de Minas Gerais (UFMG).

Kenya Noronha é doutora em Economia pelo Centro de Desenvolvimento e Planejamento Regional (Cedeplar) da Universidade Federal de Minas Gerais (UFMG). Professora adjunta da Faculdade de Ciências Econômicas (Face), Departamento de Demografia da UFMG.

\section{Endereço para correspondência}

\author{
Samara Lauar Santos \\ Universidade Federal da Paraíba, campus I \\ Via Expressa Padre Zé, 289, Castelo Branco III \\ 58051-900 - João Pessoa-PB, Brasil \\ Cássio M. Turra \\ Cedeplar - Centro de Desenvolvimento e Planejamento Regional da UFMG \\ Faculdade de Ciências Econômicas
}


Avenida Presidente Antônio Carlos, 6627, Pampulha

31270-901 - Belo Horizonte-MG, Brasil

Kenya Noronha

Cedeplar - Centro de Desenvolvimento e Planejamento Regional da UFMG

Faculdade de Ciências Econômicas

Avenida Presidente Antônio Carlos, 6627, Pampulha

31270-901 - Belo Horizonte-MG, Brasil

\begin{abstract}
Population aging and health spending: an analysis of intergenerational and intragenerational transfers in the Brazilian private health care plans

The health insurance pricing model in Brazil prohibits large variations of monthly fees by imposing strict premium rules by age. Therefore, intergenerational transfers may occur from younger age groups, who are lower-risk, to older ones. Population aging will result in a larger share of policyholders at older ages, increasing intergenerational transfers and making the current pricing structure unsustainable in the future. The aim of this article is to estimate the magnitude of intergenerational and intragenerational transfers (within the same age group) in the Brazilian private health care plans, by examining data from a representative sample of health insurance providers. We found intergenerational transfers to occur, on average, from policy holders younger than 66 years of age to older ones. Results also show significant intragenerational transfers within two of the age groups defined by existing legislation: 0 to 18 and 59 years and older. Finally, simulations using changes in the age structure over the last 15 years confirm population aging may result in larger intergenerational transfers with increasing loss-ratio over time.
\end{abstract}

Keywords: Population aging. Health expenditure. Brazilian private health care plans. Intergenerational transfers. Intragenerational transfers.

\title{
Resumen
}

Envejecimiento de la población y el gasto en salud: un análisis de las transferencias intergeneracionales e intrageneracionales en los planes privados de salud de Brasil

El modelo de fijación de precios de seguros de salud en Brasil prohíbe grandes variaciones de las tarifas mensuales mediante la imposición de reglas estrictas por franja etaria, lo que posibilita transferencias intergeneracionales desde los grupos de edades más jóvenes, que son de menor riesgo, hacia los de edades más avanzadas. El envejecimiento de la población asegurada a la salud implicará un aumento de las transferencias intergeneracionales y hará que la estructura actual de precios sea insostenible en el futuro. El objetivo de este artículo es estimar la magnitud de las transferencias intergeneracionales (entre diferentes grupos de edad) e intrageneracionales (dentro del mismo grupo etario) en los planes de salud privados brasileños, mediante el análisis de los datos de una muestra representativa de los proveedores de seguros de salud. Según los resultados obtenidos, los saldos de las transferencias intergeneracionales fueron positivos y ocurren desde los más jóvenes hacia los asegurados de 66 años o más. Los resultados muestran también la ocurrencia de transferencias intrageneracionales en dos franjas etarias definidas por la legislación vigente: de cero a 18 años y de 59 años o más. Finalmente, el 
ejercicio de retroproyección demostró que en los últimos 15 años la siniestralidad en los planos individuales presentó un aumento constante, que indica un riesgo creciente de insuficiencia de las mensualidades para costear las transferencia en el mediano plazo, a causa del envejecimiento poblacional.

Palabras clave: Envejecimiento poblacional. Gasto en salud. Planes privados de salud brasileños. Transferencias intergeneracionales. Transferencias intrageneracionales.

Recebido para publicação em 18/09/2018 Aceito para publicação em 31/10/2018 